\title{
Delayed release dexlansoprazole in the treatment of GERD and erosive esophagitis
}

This article was published in the following Dove Press journal:

Clinical and Experimental Gastroenterology

16 November 2009

Number of times this article has been viewed

\section{Eric T Wittbrodt' \\ Charles Baum² \\ David A Peura ${ }^{3}$}

'Takeda Pharmaceuticals North America, Inc., ${ }^{2}$ Takeda Pharmaceuticals International, Inc., Deerfield, IL, USA;

${ }^{3}$ University of Virginia, School of

Medicine, Charlottesville, VA, USA
Correspondence: David A Peura Emeritus Professor, University of Virginia Health Science Center, P.O. Box 800708, Charlottesville,VA 22908, USA

$\mathrm{Tel}+\mathrm{I}$ (434) 924-0316

Fax + I (434) 924-049 I

Email dap8v@hscmail.mcc.virginia.edu
Abstract: Although proton pump inhibitors (PPI) have a record of remarkable effectiveness and safety in the management of gastroesophageal reflux disease (GERD), several treatment challenges with PPI have emerged. Dexlansoprazole MR is the (R)-enantiomer of lansoprazole contained in a formulation that produces two distinct releases of drug and significantly extends the duration of active plasma concentrations and $\%$ time $\mathrm{pH}>4$ beyond that of conventional singlerelease PPI. Dexlansoprazole MR can be administered without regard to meals or the timing of meals in most patients. Dexlansoprazole MR $60 \mathrm{mg}$ demonstrated similar efficacy for healing of erosive esophagitis at 8 weeks compared with lansoprazole $30 \mathrm{mg}$, and dexlansoprazole MR $30 \mathrm{mg}$ was superior to placebo for maintenance of healed erosive esophagitis at 6 months with $99 \%$ of nights and $96 \%$ of days heartburn-free over 6 months in patients taking dexlansoprazole MR $30 \mathrm{mg}$. Superior relief of heartburn occurred in patients taking dexlansoprazole MR $30 \mathrm{mg}$ (55\% heartburn-free 24 -hour periods) vs placebo (14\%) for symptomatic nonerosive GERD. The safety profile of dexlansoprazole MR is similar to that of lansoprazole. The extended pharmacodynamic effects, added convenience, and efficacy and safety of dexlansoprazole MR offer a novel approach to gastric $\mathrm{pH}$ control in patients with acid-related disorders.

Keywords: dexlansoprazole MR, gastroesophageal reflux disease, GERD, erosive esophagitis, TAK-390MR

Gastroesophageal reflux disease (GERD) is a clinical condition characterized by persistent retrograde movement of gastric contents into the esophagus that typically manifests as burning retrosternal pain and/or regurgitation. Atypical symptoms of GERD have been described and include chronic cough, vocal hoarseness, globus, waterbrash, and throat pain. ${ }^{1}$ Pharmacologic treatment options for GERD have been directed at suppression of gastric acid production in order to reduce both volume and acidity of gastric contents. Antisecretory agents employed for the treatment of GERD include the histamine-2 receptor antagonists $\left(\mathrm{H}_{2} \mathrm{RA}\right)$ and proton pump inhibitors (PPI). $\mathrm{H}_{2} \mathrm{RA}$ possess a rapid onset of symptom control and effectively inhibit acid production; however, their use is limited by their brief duration of action and tachyphylaxis possibly owing to histamine-2 receptor up-regulation and enhanced gastrin secretion in the presence of histamine blockade. ${ }^{2}$ In contrast, PPI block the terminal step of acid production via covalent and irreversible binding of the protonated moiety of the PPI to cysteine residues on the proton pump, thereby rendering it nonfunctional, and its activity cannot be replaced until a new proton pump is synthesized. Only active proton pumps are available to be inhibited by PPI, and activation is most commonly achieved after ingestion of food. Pentagastrin has also been used experimentally to induce proton pump activation. ${ }^{3}$ 
A model of proton pump inhibition advanced by Sachs proposed that two-thirds of activated proton pumps are inhibited by PPI which leaves up to one-third of pumps uninhibited and able to secrete acid. ${ }^{4}$ In addition, not all proton pumps are activated by a meal (approximately $75 \%$ ), and it is believed that subsequent food intake permits activation of dormant pumps which also contributes to acid production. Since all PPI share the same mechanism of action and have inherently brief half-lives (approximately 1-2 hours), the potential for activation of proton pumps and acid secretion exists after their plasma concentrations diminish to subtherapeutic levels. It is important to also note that proton pumps are continuously being regenerated and the entire population of pumps within the parietal cell will typically experience turnover every 48 hours. ${ }^{4,5}$ Because food is the primary stimulus for proton pump activation, administration of PPI is commonly recommended a short time ( $<60$ minutes) before the morning meal, thereby ensuring subsequent daytime reduction in basal and meal-stimulated acid production.

While PPI have a nearly 20-year record of remarkable effectiveness and safety in the management of GERD, several treatment challenges with PPI have emerged. Symptoms of GERD have been reported to persist in between 25 and $40 \%$ of patients who take PPI for the treatment of erosive esophagitis. ${ }^{6}$ In particular, nocturnal symptoms may predominate in such patients due to persistent or de novo proton pump activity. The effectiveness of PPI for the treatment of moderate-to-severe erosive esophagitis (LA Classification C and D) is less than complete for up to $25 \%$ of patients. ${ }^{7}$ Even in those who experience complete healing of erosive esophagitis, disease relapse rates of up to $26 \%$ have been described in patients who continue PPI therapy. ${ }^{8,9}$ More than three-fourths of patients with recurrent erosive esophagitis are asymptomatic. ${ }^{9}$ Relapse is more precipitous for more severe grades of erosive disease (occurring as rapidly as 1 month post-discontinuation of medication), but all grades tend to have similarly limited durability of healing maintenance at 6 months. ${ }^{8}$ This finding has led the Cochrane Group to recommend full healing doses of PPI for maintenance of erosive esophagitis healing. ${ }^{10}$ Twice daily off-label administration of PPI is used to remedy the inadequacy of PPI effectiveness in nearly one-third of patients with GERD, ${ }^{11}$ especially in order to improve overall symptom control and relief of nocturnal heartburn. However, the consequence of this practice is increased cost of treatment and decreased compliance. Good compliance with PPI (defined as $\geq 80 \%$ fill rate of prescriptions written for PPI) resulted in significantly decreased use of the health care system and lower health care costs in GERD patients. ${ }^{12}$ As a result, perhaps one of the most important drivers of PPI effectiveness is patient adherence to therapy regimens. Several barriers to full adherence have been reported. Longterm adherence to once-daily PPI has been shown to decrease rapidly over time to approximately $50 \%$ of patients reporting low or moderate adherence within 3 months of initiation which suggests significant intermittent or as-needed use. ${ }^{13}$ In addition, the need to take each dose within 60 minutes prior to food intake (preferably a full meal in the morning) is problematic for many patients who do not eat in the morning or who take their dose during or shortly after a meal. A survey of patients taking PPI who experienced suboptimal benefit revealed that $54 \%$ of this group was taking their doses incorrectly with approximately equal numbers taking the dose on an empty stomach ( $>60$ minutes before a meal), immediately after ingestion of food, or at bedtime (presumably without subsequent food intake). ${ }^{14}$

Prescribing patterns of PPI are reportedly inconsistent with the recommendations of treatment guidelines and product labeling with more than one-third of primary care providers in one survey responding that the time of administration of PPI does not matter, and as many of $29 \%$ of gastroenterologists failing to address time of administration. ${ }^{15}$ The clinical shortcomings of PPI and the barriers to patient adherence to therapy have created an unmet medical need in the practice of GERD management. The ideal product to address these concerns would possess efficacy for erosive and nonerosive GERD consistent with the excellent record of other PPI, provide extended duration of active drug concentrations throughout the day to inhibit proton pumps activated by subsequent meals or that are generated later in the dosing interval, be administered once daily without regard to food intake, and maintain the safety and tolerability of the PPI class.

\section{Dexlansoprazole MR: product review}

Lansoprazole is a racemic mixture composed of equal proportions (50:50) of (R)-lansoprazole (also known as dexlansoprazole) and (S)-lansoprazole. These two enantiomers have been quantified separately in blood after ingestion of lansoprazole $30 \mathrm{mg}$ in healthy volunteers and it was found that the mean maximum plasma concentration $\left(\mathrm{C}_{\max }\right)$ and area under the plasma drug concentration-time curve (AUC) values were 3- to 5-fold greater for dexlansoprazole than (S)-lansoprazole. ${ }^{16}$ This suggests that the hepatic clearance of lansoprazole is stereoselective in favor 
of the (S) enantiomer leading to higher systemic exposure of and in vivo residence for dexlansoprazole as compared to its antipode, (S)-lansoprazole. Dexlansoprazole is highly bound to plasma proteins ( $96.1 \%-98.8 \%$ bound) and has an apparent volume of distribution of $40.3 \mathrm{~L}$ in subjects with GERD. ${ }^{17}$ The elimination of dexlansoprazole is via the hepatic route; biotransformation to oxidative metabolites occurs via CYP2C19 and CYP3A4 with subsequent conjugation to inactive products and elimination in the urine and feces. In vitro data suggest that CYP2C19 displays more specificity for R- than S-lansoprazole, and that CYP3A4 is more specific for S-lansoprazole. ${ }^{18}$ Dexlansoprazole does not appear to be eliminated unchanged in the urine.

The elimination half-life of dexlansoprazole is approximately 1-2 hours in healthy subjects and in patients with symptomatic GERD; this is similar to other PPI. The Dual Delayed Release formulation ( $\mathrm{DDR}^{\mathrm{TM}}$ ) employed in delivering dexlansoprazole is a more significant factor in prolonging drug residence time in the body after oral administration than the inherently slower clearance of dexlansoprazole as compared to the (S)-enantiomer. The DDR formulation delivers 2 drug inputs in the proximal and more distal small intestine. Distinct $\mathrm{pH}$-dependent releases of drug are designed to occur from two types of enteric-coated granules housed in a gelatin capsule. Upon dissolution of the outer capsule in the stomach, the first type of granule is designed to release quickly after the granules reach the proximal duodenum providing an initial drug release profile similar to that of lansoprazole and resulting in an initial peak in plasma dexlansoprazole concentrations within 1 to 2 hours of capsule ingestion. The second release from the remaining granules is designed to release farther along the gastrointestinal tract at the distal portion of the small intestine and creates a second drug peak in plasma dexlansoprazole concentrations within 4 to 5 hours of capsule ingestion. The purpose of the second release is to provide a greater amount of drug to be absorbed later in the dosing interval in order to provide extended duration of acid suppression. Therefore, the resulting time-concentration profile of dexlansoprazole MR reveals a two-peaked pattern that extends to approximately 12 hours after a dose is ingested (Figure 1).

The relationship between exposure of dexlansoprazole following administration of dexlansoprazole MR and its pharmacodynamic effect measured as intragastric $\mathrm{pH}$ has been described using an $\mathrm{E}_{\max }$ model. ${ }^{19} \mathrm{~A}$ total of 83 healthy subjects met the entry criteria for 2 studies, and were included in this combined analysis. Subjects were administered 30, 60, 90, and $120 \mathrm{mg}$ of dexlansoprazole MR in randomized crossover fashion in these two separate studies. The systemic exposure of dexlansoprazole measured as $\mathrm{C}_{\max }$ and $\mathrm{AUC}$ values was dose-proportional and time-independent. These two pharmacokinetic and pharmacodynamic studies confirmed that the $\mathrm{DDR}^{\mathrm{TM}}$ technology used in the dexlansoprazole MR formulation prolonged drug exposure; pharmacokinetic and pharmacodynamic modeling suggested that doses lower than $30 \mathrm{mg}$ may result in therapeutically suboptimal intragastric $\mathrm{pH}$ control. Furthermore, it was demonstrated that doses higher than $90 \mathrm{mg}$ would be unlikely to provide additional clinically meaningful pharmacologic response.

In a retrospective analysis using data from 2 separate but similarly designed studies the pharmacokinetic profiles of dexlansoprazole MR $60 \mathrm{mg}$ and lansoprazole $60 \mathrm{mg}$ were compared after 5 days of dosing in healthy volunteers, demonstrating that the $t_{\max }$ for both regimens occurred 1 to 2 hours after administration, and that the second peak for dexlansoprazole MR occurred 4 to 5 hours after administration. ${ }^{20}$ The results from this single post-hoc analysis also showed that the mean residence time for dexlansoprazole MR was nearly double that of lansoprazole at equivalent doses of $60 \mathrm{mg}$ once daily ( 5.5 hours vs 2.9 hours, respectively). ${ }^{21}$

The pharmacokinetics, pharmacodynamics, and safety of three dosing regimens of dexlansoprazole MR (60, 90, and $120 \mathrm{mg}$ ) and lansoprazole $30 \mathrm{mg}$ were assessed in an open-label, multiple-dose, single-center, four-period, crossover study in 40 subjects. ${ }^{22}$ After 5 days of once daily administration dexlansoprazole MR $60 \mathrm{mg}$ produced statistically significantly greater mean 24-hour intragastric $\mathrm{pH}$ compared to lansoprazole $30 \mathrm{mg}$ (4.55 vs 4.13 , respectively, $P<0.001$ ); a statistically significant increase in $\%$ time 24 -hour intragastric $\mathrm{pH}>4$ was also observed (71\% vs $60 \%$, respectively, $P<0.01$ ) (Figure 2). The $90 \mathrm{mg}$ dose of dexlansoprazole MR produced 24-hour intragastric $\mathrm{pH}>4$ for $70 \%$ of the time. The pharmacodynamic effect of dexlansoprazole MR $120 \mathrm{mg}$ was similar to that of the $90 \mathrm{mg}$ dose. As a result, the $120 \mathrm{mg}$ dose was not pursued for clinical development. The clinical significance of these differences remains unknown, but the $\mathrm{DDR}^{\mathrm{TM}}$ formulation of dexlansoprazole MR appears to provide pharmacodynamic benefit beyond that of lansoprazole most likely due to the extended duration of effective plasma concentration.

The impact of food on the pharmacokinetics and pharmacodynamics of dexlansoprazole MR was evaluated in 46 healthy subjects who completed all dosing regimens in a randomized, 4-period, open-label, crossover study. ${ }^{23}$ Placebo was administered in 4 regimens: after a 10-hour fast, 30 minutes before, 5 minutes before, or 30 minutes after 

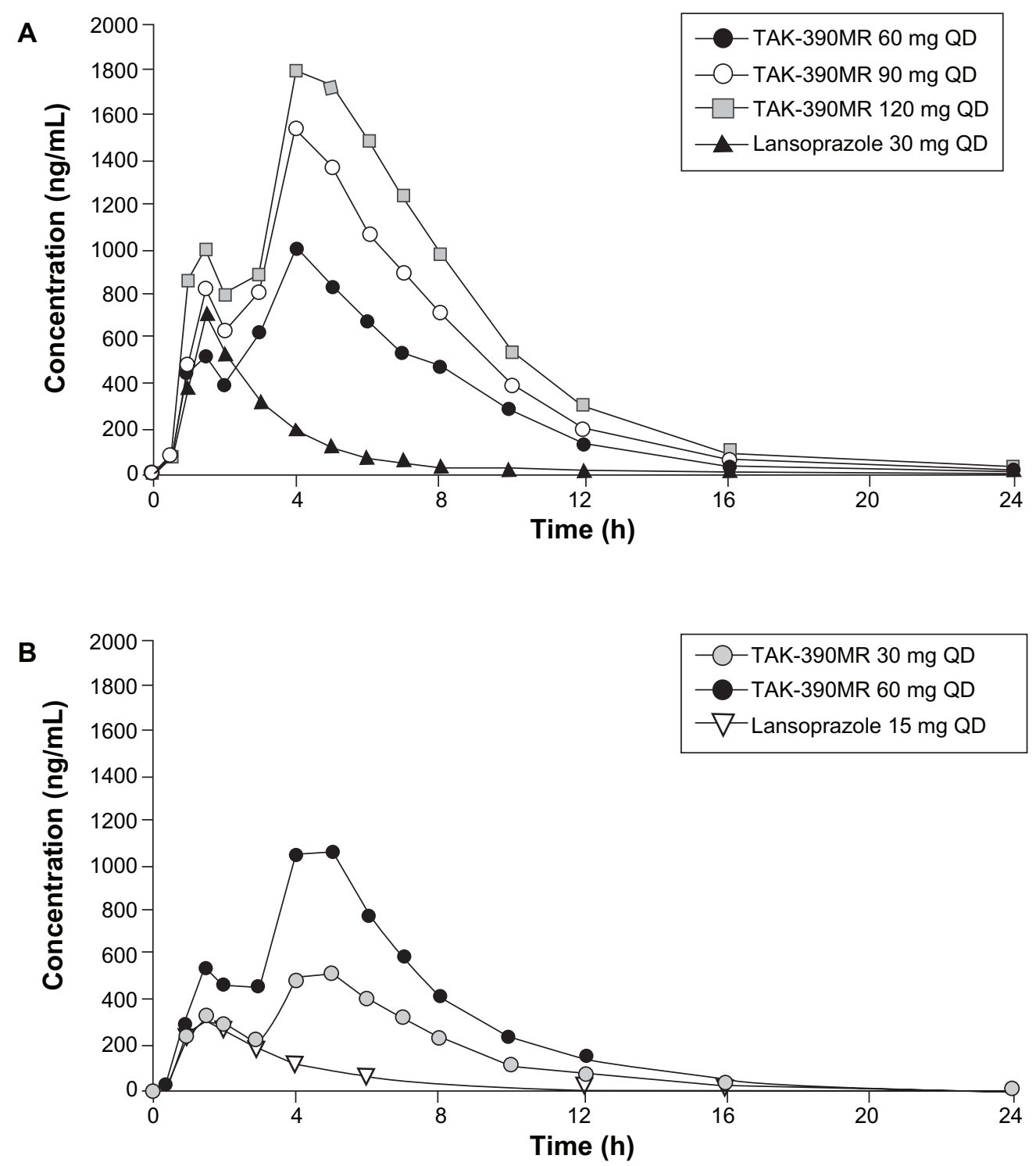

Figure I Mean time-concentration profiles of dexlansoprazole MR on Day 5. Adapted by permission from Informa Healthcare Vakily M, Zhang W,Wu J, Atkinson SN, Mulford D. Pharmacokinetics and pharmacodynamics of a known active PPI with a novel dual delayed release technology, dexlansoprazole MR: a combined analysis of randomized controlled clinical trials. Curr Med Res Opin. 2009;25(3):627-638. ${ }^{19}$ Copyright (c) 2009.

a high-fat breakfast on Day 1; dexlansoprazole MR $90 \mathrm{mg}$ was administered in the same fashion for each crossover period on Day 3. Plasma concentrations of dexlansoprazole were measured on Day 3 and 24-hour intragastric $\mathrm{pH}$ was assessed on Days 1 and 3. Pharmacokinetics of dexlansoprazole in the fed conditions (administered 5 minutes before and 30 minutes after a high-fat breakfast) when compared to the fasted state displayed at least a 1.09-fold greater increase (using the point estimates) in $\mathrm{C}_{\text {max }}$ and $\mathrm{AUC}$ for the fed state (Figure 3). Thus, the bioavailability was increased in the fed vs fasted state. The data also showed that the systemic exposure of dexlansoprazole after dexlansoprazole MR was administered 30 minutes before a high-fat breakfast was bioequivalent to that obtained following administration of dexlansoprazole MR under fasted state. The differences in the pharmacodynamic parameters measured as mean 24-hour intragastric $\mathrm{pH}$ and \% time 24-hour intragastric $\mathrm{pH}>4$ were not considered to be clinically meaningful between any of the periods which signified both a lack of food effect and a lack of effect of timing of food intake relative to dosing with dexlansoprazole MR on intragastric $\mathrm{pH}$ profile.

Because PPI are traditionally administered before the morning meal, it is important to determine if a PPI with extended release properties such as dexlansoprazole MR can be taken at different times during the day which may offer greater dosing flexibility. The influence of time of day of 


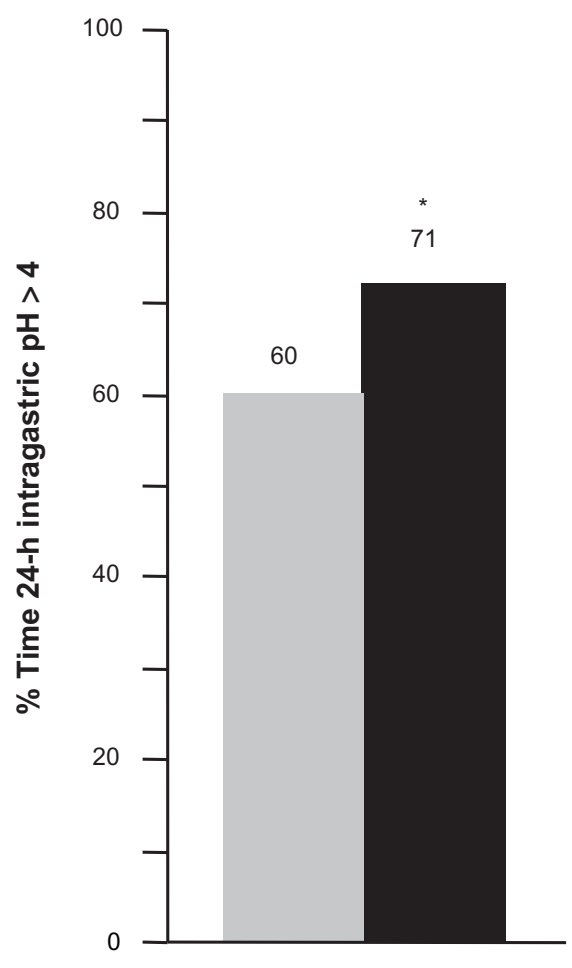

Day 5

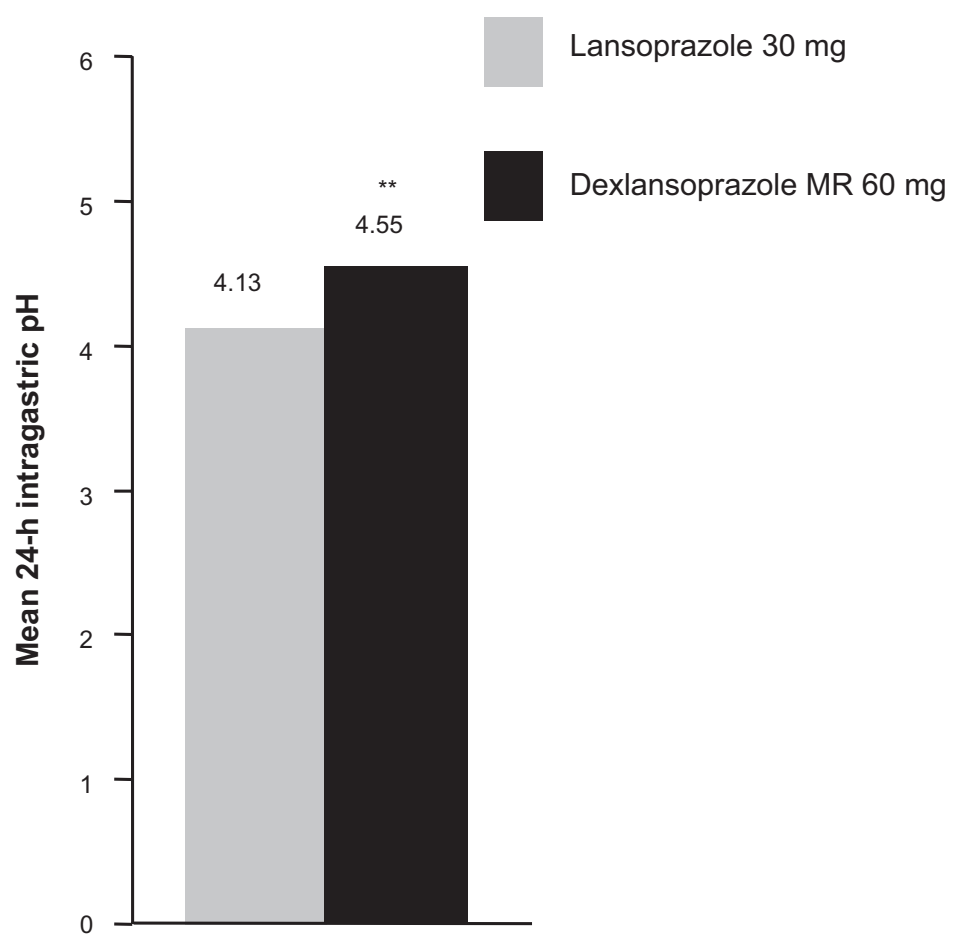

Day 5

Figure 2 Mean \% time intragastric $\mathrm{pH}>4$ and mean 24-hour intragastric $\mathrm{pH}$ with dexlansoprazole MR $60 \mathrm{mg}$ vs lansoprazole $30 \mathrm{mg}$ on Day $5 .{ }^{19}$ $* P<0.01$, $* * P<0.001$.

Note: $P$-values are from the tests of the differences in least square means between a given dexlansoprazole MR and the LAN regimen.

dexlansoprazole MR administration on pharmacokinetic and pharmacodynamic variables was assessed in 44 healthy subjects who completed all regimens in a 4-period, randomized, crossover fashion in which drug was administered daily for five days 30 minutes before breakfast, lunch, dinner, or a bedtime snack. Plasma drug concentrations and 24-hour intragastric $\mathrm{pH}$ were assessed on Day 5 of each period. ${ }^{24}$ Systemic exposure of dexlansoprazole when dosed before breakfast was bioequivalent when dosed before lunch, dinner or an evening snack, and minimal but statistically significant differences were found in mean 24-hour intragastric $\mathrm{pH}$ between dosing at breakfast and at lunch $(0.2$ difference in $\mathrm{pH})$ and in $\%$ time 24-hour intragastric $\mathrm{pH}>4$ between dosing at breakfast and at bedtime snack (7\% difference). No other significant differences in 24-hour intragastric $\mathrm{pH}$ were found between breakfast and the other mealtimes. Therefore, the dosing versatility of dexlansoprazole MR appears to extend beyond the lack of an effect by food into the realm of dose timing flexibility.

The impact of dose timing on the pharmacodynamic effects of other PPI has been previously studied. Rabeprazole dose timing was studied in a crossover fashion in 20 GERD patients, and a significantly greater $\%$ time intragastric $\mathrm{pH}>4$ was observed when the dose was given once daily in the morning vs the evening. ${ }^{25}$ Dosing lansoprazole in the morning produced no differences in intragastric $\mathrm{pH}$ (mean 24-h $\mathrm{pH}$ or $\%$ time $\mathrm{pH}>4$ ) than evening dosing in healthy subjects in one study. ${ }^{26}$ However, morning dosing of lansoprazole in another study was significantly more effective than evening dosing at intragastric $\mathrm{pH}$ control for all time periods during the day except for overnight, when the two dosing methods were comparable. ${ }^{27}$

An alternative method of dexlansoprazole administration was studied in 50 healthy subjects in a two-period, randomized, crossover study where dexlansoprazole MR $90 \mathrm{mg}$ was ingested after a 10-hour fasting period as either an intact capsule with water or after the capsule was opened and the granules were sprinkled over applesauce and swallowed. ${ }^{28}$ No significant differences in either AUC or $\mathrm{C}_{\max }$ were found between the two methods, and bioequivalence was established for dexlansoprazole MR regardless of whether given whole with water or sprinkled over applesauce.

Drug-drug interactions remain a potential concern for any compound that undergoes extensive hepatic metabolism, 


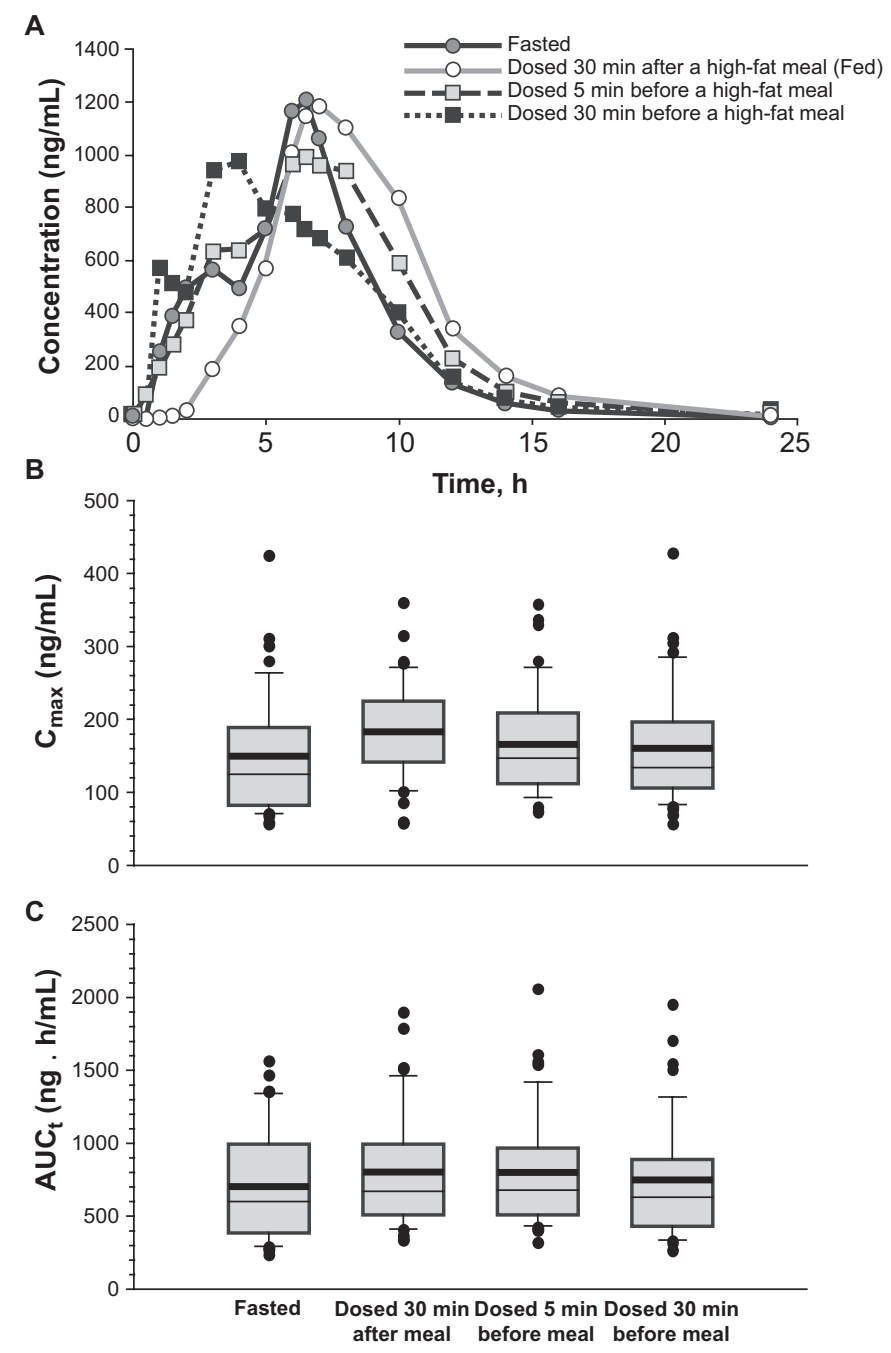

Figure 3 Mean dexlansoprazole plasma concentration-time profiles A), $C_{\max }$ B), and AUC C) following a single dose of dexlansoprazole MR 90 mg under fasted and various fed conditions. Reproduced with permission from Lee RD, Vakily M, Mulford D, Wu J, Atkinson SN. Clinical trial: the effect and timing of food on the pharmacokinetics and pharmacodynamics of dexlansoprazole MR, a novel dual delayed release formulation of a proton pump inhibitor - evidence for dosing flexibility. Aliment Pharmacol Ther. 2009; 29(8):824-833.23 Copyright (C) 2009 Wiley-Blackwell.

including PPI. Four separate studies were conducted in healthy subjects in which dexlansoprazole MR $90 \mathrm{mg}$ was given once daily for 9 to 11 days with a single dose of a test substrate. The test substrates for the in vivo assessment of CYP enzyme activity included diazepam $5 \mathrm{mg}$ (a substrate for CYP2C19 and CYP3A), phenytoin $250 \mathrm{mg}$ (CYP2C9 and CYP2C19), theophylline (given as intravenous aminophylline $400 \mathrm{mg}, \mathrm{CYP} 1 \mathrm{~A} 2)$, and warfarin $25 \mathrm{mg}$ (CYP2C9). ${ }^{29}$ No significant differences in $\mathrm{C}_{\text {max }}$ or AUC of any substrate were detected when given concomitantly with dexlansoprazole MR. Furthermore, the pharmacodynamic impact of coadministration of dexlansoprazole MR with warfarin as measured by change in INR was not significant. Therefore, no significant pharmacokinetic and pharmacodynamic (for warfarin only) drug-drug interactions were found in these studies with dexlansoprazole MR. At the time of this review no studies have been conducted with dexlansoprazole and clopidogrel, so the effect of the two drugs when given together is unknown.

Due to complete metabolism in the liver to inactive metabolites and the absence of unchanged drug excreted in the urine, dexlansoprazole MR is not expected to undergo accumulation in kidney dysfunction, and no dose adjustment is required in patients with renal impairment.

Accumulation of dexlansoprazole concentrations occurred in subjects with moderate (Child Pugh Class B) hepatic impairment, but not in mild impairment (Child Pugh Class A). ${ }^{30}$ Due to this finding, studies were not conducted in patients with severe hepatic impairment. Thus, the lower dexlansoprazole MR dose of $30 \mathrm{mg}$ should be considered in moderate hepatic impairment, and no dosage adjustment is required in mild impairment. 
Dexlansoprazole MR pharmacokinetics were not significantly altered in elderly patients, ${ }^{31}$ women, ${ }^{31}$ or GERD patients. ${ }^{32}$

\section{Dexlansoprazole MR: clinical studies}

The clinical development program for dexlansoprazole MR was the largest for any PPI to date and comprised 6 pivotal studies in more than 4500 patients. The goals of this program were to establish the efficacy and safety of dexlansoprazole MR in the treatment and maintenance of erosive esophagitis and in the control of symptomatic nonerosive GERD.

\section{Healing of erosive esophagitis}

Two identically designed trials evaluated the efficacy and safety of dexlansoprazole MR vs lansoprazole in the healing of erosive esophagitis. ${ }^{33}$ Both trials were randomized and double-blinded and compared dexlansoprazole MR $60 \mathrm{mg}$ and $90 \mathrm{mg}$ with lansoprazole $30 \mathrm{mg}$ once daily. All doses were given once daily within 60 minutes of the morning meal to maintain blinding, and the duration of treatment was 8 weeks. All patients were adults (age $>18$ years) with endoscopically proven erosive esophagitis. Exclusion criteria included the presence of Helicobacter pylori infection or Barrett's esophagus. Esophagogastroduodenoscopy (EGD) was performed at baseline (to establish the presence of esophageal erosions) and at 4 and 8 weeks. The primary endpoint was the percentage of patients with endoscopic evidence of healing at 8 weeks, and secondary endpoints included the percentage of subjects with moderate-to-severe (Los Angeles [LA] Grades C and D) erosive esophagitis who were healed at 8 weeks, and all grades healed at 4 weeks. The target proportion of patients with LA Grade C and D disease was $30 \%$ as consistent with FDA guidance that this subgroup of disease presents specific challenges to healing. The symptoms of erosive esophagitis were recorded by diary twice daily: upon awakening each morning to capture any symptoms experienced overnight and upon retiring each evening to capture any symptoms experienced while awake. The rigor of this recording method was intended to minimize the recall bias that may arise from once daily symptom recording. The primary method of analysis of the healing rate was the crude rate; this analysis method classifies any subject who does not complete the study (eg, no data for week 8 endoscopy) as a complete treatment failure. This is in contrast to life-table analysis, the statistical methodology historically used in PPI trials, in which the probability is calculated that a patient would have healed had he remained in the study and received the final EGD. As such, in life-table analysis the patient who does not complete the trial is considered a partial failure. The crude rate is an inherently more stringent analysis method, and typically yields lower healing rates than life-table. Both dexlansoprazole MR erosive esophagitis healing trials were designed to test for noninferiority; the dexlansoprazole MR doses shown to be noninferior were then tested for superiority to lansoprazole $30 \mathrm{mg}$ for primary and secondary efficacy endpoints. For each study, a sample size of 520 patients per treatment group provided at least $95 \%$ power at the 0.025 level of significance to detect noninferiority between dexlansoprazole MR and lansoprazole, assuming equal healing rates of $87 \%$ at Week 8 .

Baseline demographics were not significantly different between any of the groups in either study. Erosive esophagitis healing rates at week 8 for both dexlansoprazole MR doses were superior to lansoprazole in one study (Study 1); $60 \mathrm{mg}$ of dexlansoprazole MR was noninferior and $90 \mathrm{mg}$ was superior to lansoprazole in the other study (Figure 4). Healing at week 4 was $>64 \%$ for all groups using both crude rate and life-table analysis methods. Healing of moderate-to-severe erosive esophagitis was significantly greater with dexlansoprazole MR $60 \mathrm{mg}$ than lansoprazole in Study 1 and both doses were noninferior to lansoprazole in Study 2. The median percentage of 24-hour heartburnfree days was greater than $80 \%$ in patients who received either dose of dexlansoprazole MR; this was comparable to lansoprazole.

\section{Maintenance of erosive esophagitis healing}

Subjects who experienced healing of erosive esophagitis in either of the two healing studies mentioned previously were eligible for enrollment in one of two studies designed to evaluate the maintenance of healing over a 6-month period. One study compared dexlansoprazole MR $30 \mathrm{mg}$ and $60 \mathrm{mg}$ with placebo ${ }^{34}$ and the other study compared $60 \mathrm{mg}$ and $90 \mathrm{mg}$ doses with placebo. ${ }^{35}$ The placebo-controlled design was consistent with the standard comparator of other esophagitis healing maintenance studies. The final endoscopy of the previous healing study was considered the baseline assessment of healing for this maintenance study and was followed by endoscopies at 1,3, and 6 months to document persistence of healing. The primary efficacy endpoint was the percentage of subjects who maintained healed erosive esophagitis at 6 months. Secondary efficacy endpoints included the percentage of days without daytime or nighttime heartburn and the percentage of nights without heartburn. Symptoms 


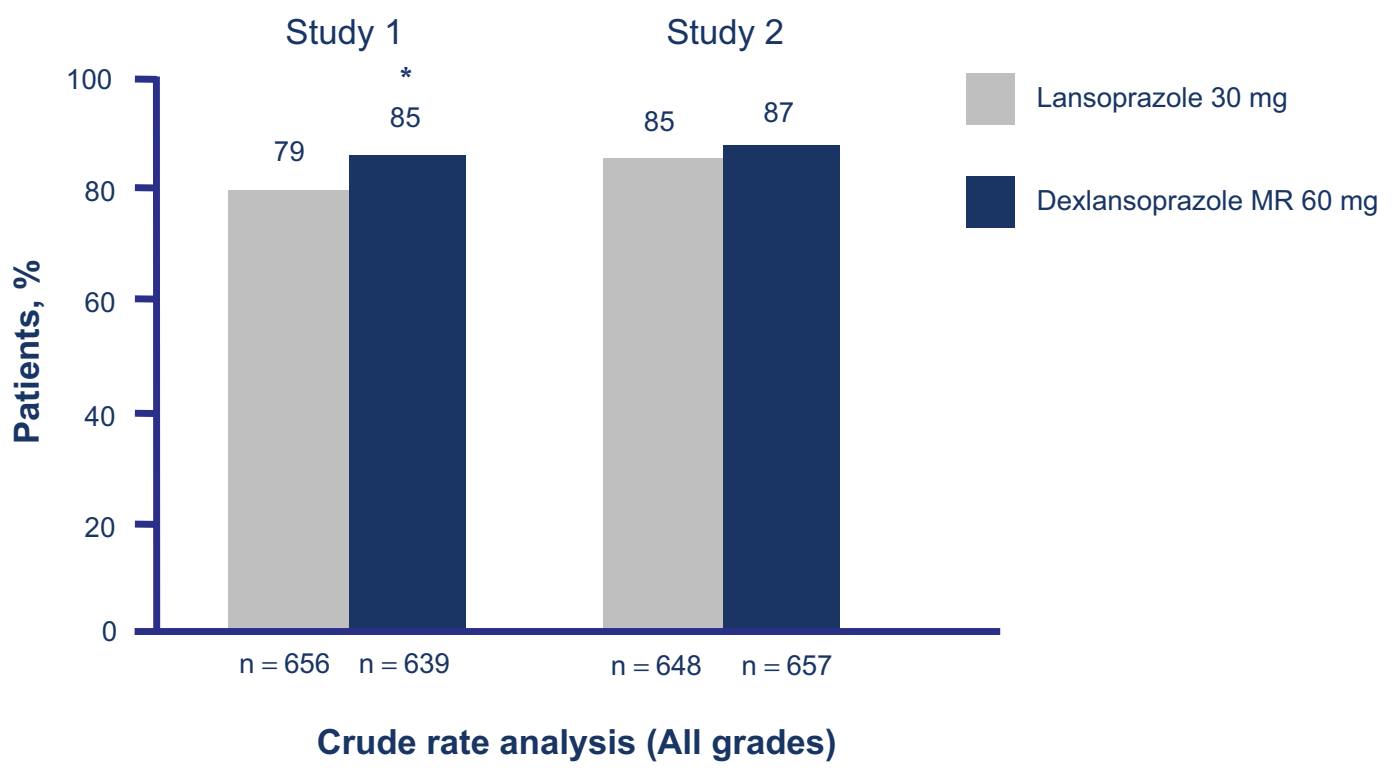

Figure 4 Comparative 8-week crude erosive esophagitis healing rates for dexlansoprazole MR and lansoprazole. ${ }^{33}$ $P=0.004$ vs lansoprazole.

were recorded by subjects twice daily in a manner identical to the erosive esophagitis healing studies.

The enrollment of the study that compared dexlansoprazole MR $30 \mathrm{mg}$ and $60 \mathrm{mg}$ with placebo was 445 subjects, and the withdrawal rate from study medication was $83 \%$ for the placebo group and $34 \%$ for each dexlansoprazole MR group, mostly due to relapse of erosive esophagitis. Maintenance of healing rates were significantly higher for both dexlansoprazole MR doses compared to placebo, and this finding was consistent for all grades of erosive esophagitis and for moderate-to-severe disease. The median percentage of 24-hour heartburn-free days and median percentage of nights without heartburn was statistically significantly higher for all doses of dexlansoprazole MR than placebo, with $96 \%$ of 24-hour periods and $99 \%$ of nights being reported as heartburn-free over 6 months for dexlansoprazole MR $30 \mathrm{mg}$ vs $29 \%$ of 24-hour periods and $72 \%$ of nights for placebo (Figure 5).

\section{Symptomatic relief of nonerosive GERD}

The control of nonerosive GERD symptoms remains a therapeutic challenge for practitioners, because the true etiology of the symptoms may or may not be due to acid or may be unknown. A clinical trial compared two different doses of dexlansoprazole MR (30 and $60 \mathrm{mg}$ ) with placebo in subjects with normal esophageal mucosa on EGD. ${ }^{36}$ This study identified patients with heartburn-predominant complaints for at least 6 months and for 4 of the 7 days prior to screening for enrollment, but no minimal severity of symptoms was required. Besides EGD, no objective assessments of esophageal disease such as pH-metry were conducted and no attempts were made to identify or exclude patients with functional heartburn. Study medication was administered in a blinded fashion once daily in the morning for 28 days. Subjects recorded heartburn symptom assessments twice daily as described for the erosive esophagitis healing and maintenance studies, and investigator assessments occurred at baseline and at 2 and 4 weeks of the study. The primary endpoint was the percentage of 24-hour periods that were free of heartburn symptoms over 28 days, and the secondary endpoint was the percentage of daytime periods and nighttime periods without heartburn. The results demonstrated that a majority of the 24-hour periods were heartburn-free in the groups that received dexlansoprazole MR (median percentage $54.9 \%$ for the $30 \mathrm{mg}$ group) compared with $18.5 \%$ for the placebo group (Figure 6). The dexlansoprazole MR $30 \mathrm{mg}$ group also experienced significantly greater nighttime periods (median percentage of nights $80.8 \%$ vs $51.7 \%$ for placebo) and daytime periods (median percentage of days $63.0 \%$ vs $26.9 \%$ for placebo) that were symptom-free. It is important to note that no nighttime symptom requirement was necessary for enrollment into the study; this may partially explain the relatively large placebo response for this endpoint. The percentage of patients during the study who experienced 24-hour heartburn-free days over the first 3 days of treatment was significantly greater for dexlansoprazole MR treatment groups than placebo. The percentage of patients with 24-hour heartburn-free days by each study day is presented in Figure 7. 


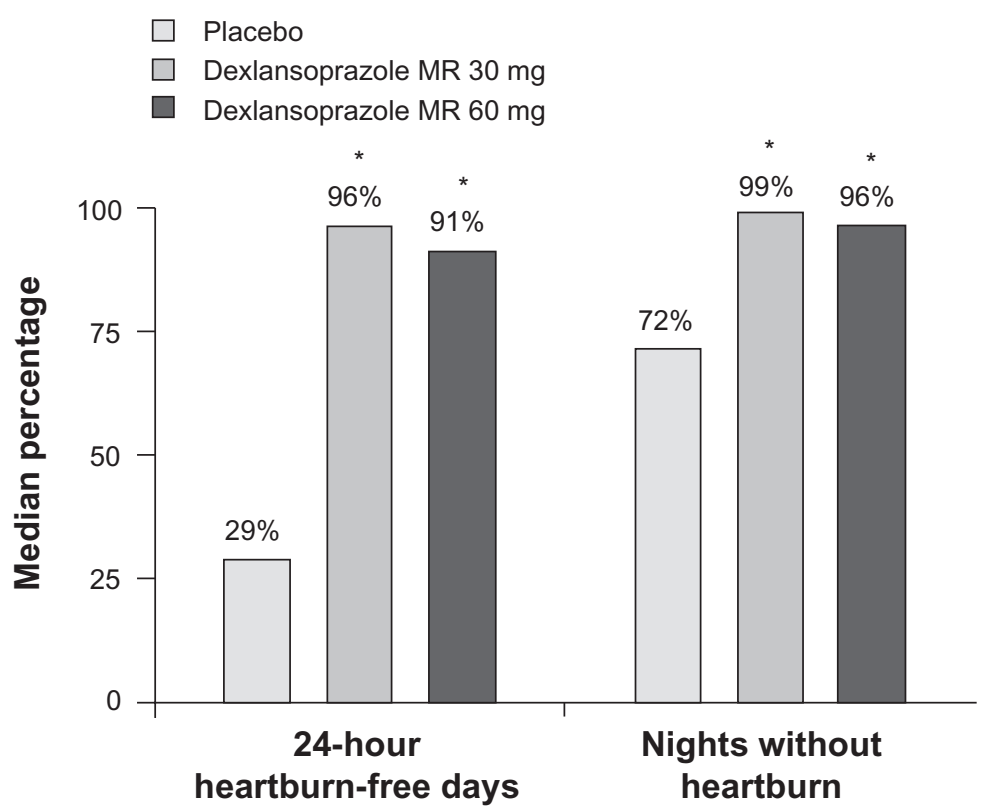

Figure 5 Median percentage of 24-hour heartburn-free days and median percentage of nights without heartburn during treatment. $P<0.0025$ vs placebo (Hochberg's procedure; Wilcoxon rank sum tests).

Reproduced with permission from Metz DC, Howden CW, Perez MC, Larsen L, O'Neil J, Atkinson SN. Clinical trial: dexlansoprazole MR, a proton pump inhibitor with dual delayed-release technology, effectively controls symptoms and prevents relapse in patients with healed erosive oesophagitis. Aliment Pharmacol Ther. 2009;29(7):742-754.34 Copyright @ 2009 Wiley-Blackwell.

\section{Dexlansoprazole MR: safety and tolerability}

The safety and tolerability of dexlansoprazole MR was evaluated in more than 4500 patients in seven trials of the phase 3 clinical development program. Treatment-emergent adverse events were reported in which any such event that occurred after the ingestion of the first dose of study medication was recorded and analyzed. The strictness of this reporting method contrasts with reporting of treatmentrelated events which requires the investigator to deem an

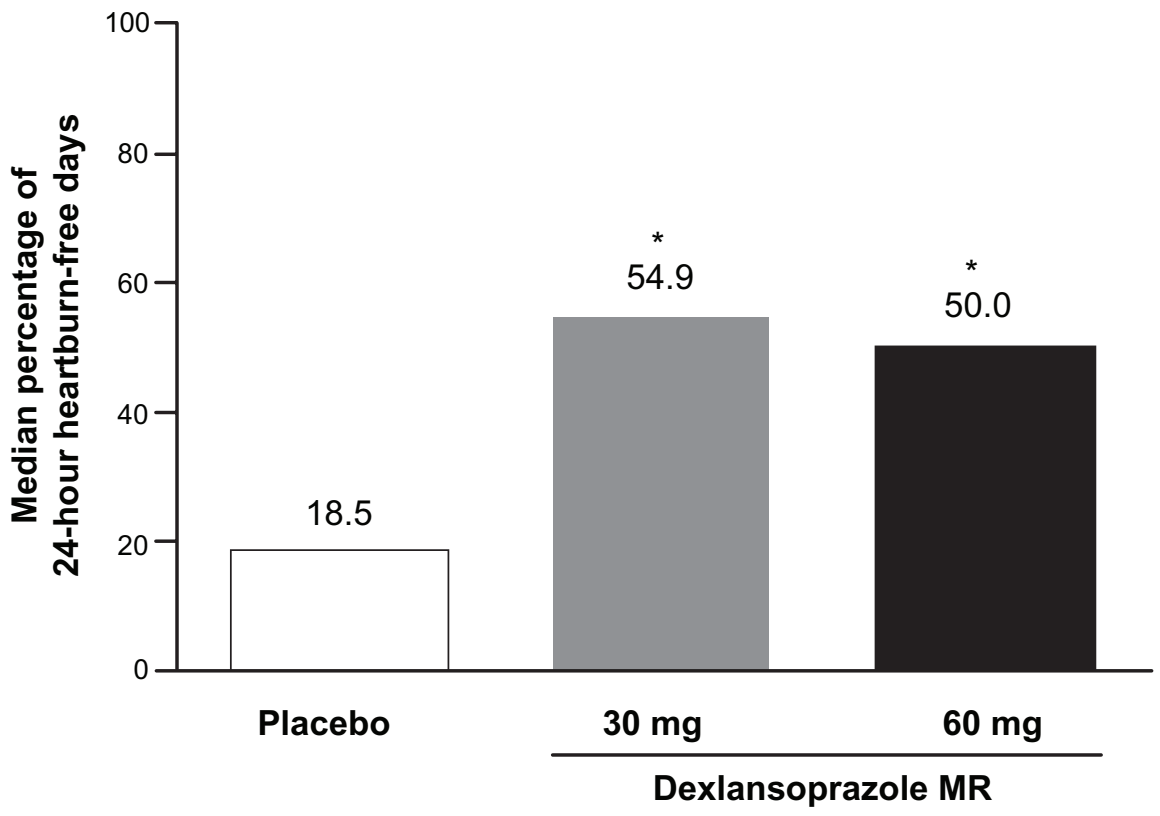

Figure 6 Median percentage of 24-hour heartburn-free periods with dexlansoprazole MR vs placebo in nonerosive GERD. $* P<0.0000$ I.

Reproduced with permission from Fass R, Chey WD, Zakko SF, et al. Clinical trial: the effects of the proton pump inhibitor dexlansoprazole MR on daytime and nighttime heartburn in patients with nonerosive reflux disease. Aliment Pharmacol Ther. 2009;29(I2): I 26I-1272. ${ }^{36}$ Copyright (C) 2009 Wiley-Blackwell. 


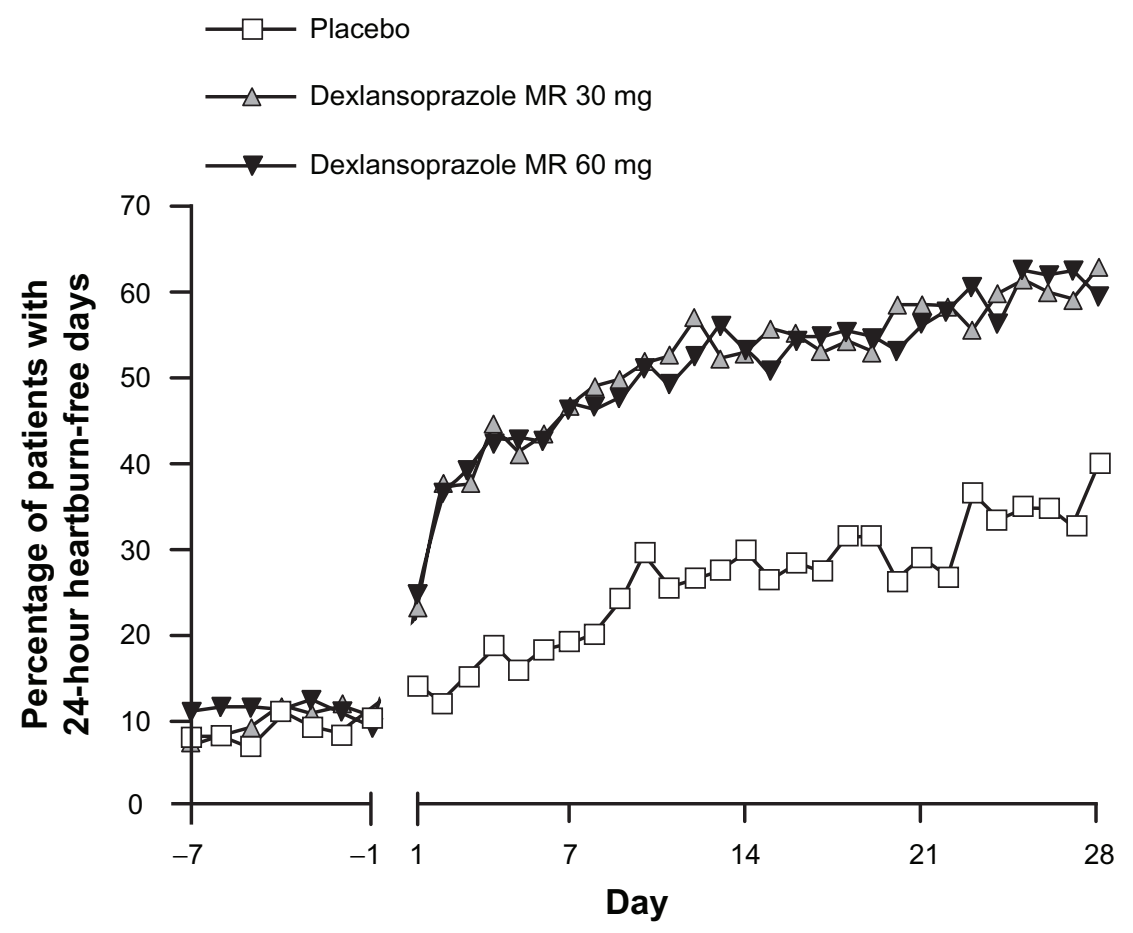

Figure 7 Percentage of patients with 24-hour heartburn-free days by each study day in nonerosive GERD. Notes: There was no comparison made for each study day and hence no statistical significance is reported. Reproduced with permission from Fass R, Chey WD, Zakko SF, et al. Clinical trial: the effects of the proton pump inhibitor dexlansoprazole MR on daytime and nighttime heartburn in patients with nonerosive reflux disease. Aliment Pharmacol Ther. 2009;29(I2): I 26I-1272. ${ }^{36}$ Copyright (C) 2009 Wiley-Blackwell.

adverse event to be related to the study medication in order to be reported. The most commonly reported treatmentemergent adverse events (with a frequency of $\geq 2 \%$ ) from all clinical studies of dexlansoprazole MR are presented in Table 1. Diarrhea was the most common adverse event leading to discontinuation form dexlansoprazole therapy in controlled clinical studies $(0.7 \%){ }^{20}$

The elevation of plasma gastrin concentrations by PPI is a well-established class effect that is due to the compensatory increase in afferent hormonal input of parietal cell acid production. The trophic effects of gastrin on the gastric mucosa and evidence of ECL-cell hyperplasia in animals have led to potential controversy about the long-term use of PPI in humans. Mean plasma gastrin $\mathrm{AUC}_{24}$ increased by approximately 3.5 -fold compared with baseline values after 5 days of dosing with dexlansoprazole MR $90 \mathrm{mg}$ or $120 \mathrm{mg}$; this magnitude of increase was similar to that of lansoprazole $30 \mathrm{mg}$ in a crossover study in healthy subjects. ${ }^{37}$ Gastrin parameters started to decline within 3 days after drug discontinuation, and returned to baseline within 7 days after the last dose of drug. Thus, the changes in gastrin associated with dexlansoprazole MR appeared to be modest, reversible, unrelated to dose, and similar to other PPI. Elevations in serum gastrin concentrations were higher in the dexlansoprazole MR groups than in the lansoprazole group in the erosive esophagitis healing studies, but were within the expected range for PPI. ${ }^{33}$ Gastrin elevations also occurred in all dexlansoprazole MR groups in the maintenance and nonerosive GERD studies compared to placebo. ${ }^{34,36}$ These elevations were also within the range expected for patients receiving PPI.

Gastric biopsies obtained at the final visit in patients enrolled in either of the maintenance of erosive esophagitis studies revealed no findings of neuroendocrine cell proliferation or adenocarcinoma. ${ }^{34,35}$

Finally, no changes in the cardiac rhythm (including Q-T interval) were detected in healthy volunteers who received a single dose of dexlansoprazole MR $90 \mathrm{mg}$ or $300 \mathrm{mg} .{ }^{38}$ No consistent, clinically important changes in laboratory results, vital signs, or physical examinations were observed.

\section{Summary and conclusions}

Dexlansoprazole MR is a PPI administered by a unique delivery system that extends the duration of active plasma concentrations of drug beyond conventional PPI. It is available in two dosage strengths, 30 and $60 \mathrm{mg}$, and is currently approved for 3 clinical indications: healing of 
Table I Most common adverse reactions $(\geq 2 \%)$ that occurred at a higher incidence for dexlansoprazole MR than placebo in controlled studies ${ }^{17}$

\begin{tabular}{|c|c|c|c|c|c|}
\hline Adverse reaction & $\begin{array}{l}\text { Placebo } \\
(\mathbf{N}=\mathbf{8 9 6}) \%\end{array}$ & $\begin{array}{l}\text { Dexlansoprazole } \\
\text { MR } 30 \mathrm{mg} \\
(\mathrm{N}=455) \%\end{array}$ & $\begin{array}{l}\text { Dexlansprazole } \\
\text { MR } 60 \mathrm{mg} \\
(\mathrm{N}=2218) \%\end{array}$ & $\begin{array}{l}\text { Dexlansoprazole } \\
\text { MR total } \\
(\mathbf{N}=\mathbf{2 6 2} \text { I) \% }\end{array}$ & $\begin{array}{l}\text { Lansoprazole } \\
30 \mathrm{mg} \\
(\mathbf{N}=1363) \%\end{array}$ \\
\hline Diarrhea & 2.9 & 5.1 & 4.7 & 4.8 & 3.2 \\
\hline Abdominal pain & 3.5 & 3.5 & 4.0 & 4.0 & 2.6 \\
\hline Nausea & 2.6 & 3.3 & 2.8 & 2.9 & 1.8 \\
\hline $\begin{array}{l}\text { Upper respiratory tract } \\
\text { infection }\end{array}$ & 0.8 & 2.9 & 1.7 & 1.9 & 0.8 \\
\hline Vomiting & 0.8 & 2.2 & 1.4 & 1.6 & I.I \\
\hline Flatulence & 0.6 & 2.6 & 1.4 & 1.6 & 1.2 \\
\hline
\end{tabular}

erosive esophagitis at a dose of $60 \mathrm{mg}$ orally once daily for up to 8 weeks, maintenance of erosive esophagitis healing at a dose of $30 \mathrm{mg}$ orally once daily for up to 6 months, and relief of symptomatic nonerosive GERD at a dose of $30 \mathrm{mg}$ orally once daily for 4 weeks. In 2 large active-control studies of dexlansoprazole MR it showed healing rates of all grades of erosive esophagitis consistent with lansoprazole, and this healing was maintained for up to 6 months in nearly two-thirds of patients at either dose in another placebocontrolled study. In addition, dexlansoprazole MR provided complete relief of heartburn symptoms for a median of 55\% of 24-hour periods over 28 days in patients with symptomatic nonerosive GERD. The safety profile of dexlansoprazole MR is similar to that of lansoprazole. Because dexlansoprazole MR can be taken without regard to food or time of day it is more convenient for individuals who find compliance with meal-associated dosing of medication difficult or eat at irregular times. The prolonged duration of acid suppression provided by dexlansoprazole MR addresses the short half-life of conventional PPI and offers a novel approach to extending gastric $\mathrm{pH}$ control in patients with selected acid-related disorders.

\section{Disclosures}

Drs Baum and Wittbrodt are employees of Takeda Pharmaceuticals, North America, Deerfield, IL, USA.

Dr Peura has served as a consultant, member of the speakers bureau, and an advisory board member for Takeda Global Research and Development Center, Inc. Deerfield, IL, USA (TAP Pharmaceutical Products Inc., Lake Forest, IL, USA is now a part of Takeda Global Research and Development Center, Inc.) as an advisory board member and consultant for Novartis Consumer Health Inc., and as a member of the speakers bureau for AstraZeneca and Santarus.

The manuscript was written by the authors.

\section{References}

1. Kahrilas PJ, Shaheen NJ, Vaezi MF; American Gastroenterological Association Institiute; Clinical Practice and Quality Management Committee. American Gastroenterological Association Institute technical review on the management of gastroesophageal reflux disease. Gastroenterology. 2008;135(4):1392-1413.

2. Gillen D, McColl KEL. Problems related to acid rebound and tachyphylaxis. Best Pract Res Clin Gastro. 2001;15(3):487-495.

3. Metz DC, Ferron GM, Pau J, et al. Proton pump activation in stimulated parietal cells is regulated by gastric acid secretory capacity: a human study. J Clin Pharmacol. 2002;42(5):512-519.

4. Sachs G. Proton pump inhibitors and acid-related diseases. Pharmacotherapy. 1997;17(1):22-37.

5. Sachs G, Shin JM, Briving C, Wallmark B, Hersey S. The pharmacology of the gastric acid pump: the H+, K+ ATPase. Annu Rev Pharmacol Toxicol. 1995;35:277-305.

6. Katz PO, Scheiman JM, Barkun AN. Review article: acid-related disease - what are the unmet clinical needs? Aliment Pharmacol Ther. 2006;23 Suppl 2:9-22.

7. Fennerty MB, Johansen JF, Hwang C, Sostek M. Efficacy of esomeprazole $40 \mathrm{mg}$ vs lansoprazole $30 \mathrm{mg}$ for healing moderate to severe erosive oesophagitis. Aliment Pharmacol Ther. 2005;21(4):455-463.

8. Lauritsen K, Devière J, Bigard MA, et al. Esomeprazole $20 \mathrm{mg}$ and lansoprazole $15 \mathrm{mg}$ in maintaining healed reflux oesophagitis: Metropole study results. Aliment Pharmacol Ther. 2003;17(3):333-341.

9. Kovacs TO, Freston JW, Haber MM, Atkinson S, Hunt B, Peura DA Long-term quality of life improvement in subjects with healed erosive esophagitis: treatment with lansoprazole. Dig Dis Sci. 2009 Jul 7. [Epub ahead of print].

10. Donnellan C, Sharma N, Preston C, Moayyedi P. Medical treatments for the maintenance therapy of reflux oesophagitis and endoscopic negative reflux disease. Cochrane Database Syst Rev. 2005;(2):CD003245.

11. Inadomi JM, McIntyre L, Bernard L, Fendrick AM. Step-down from multiple- to single-dose proton pump inhibitors (PPIs): a prospective study of patients with heartburn or acid regurgitation completely relieved with PPIs. Am J Gastroenterol. 2003;98(9):1940-1944.

12. Gosselin A, Luo R, Lohoues $\mathrm{H}$, et al. The impact of proton pump inhibitor compliance on health-care utilization and costs in patients with gastroesophageal reflux disease. Value Health. 2009;12(1):34-39.

13. Van Soest EM, Siersema PD, Dieleman JP, Sturkenboom MC, Kuipers EJ. Persistence and adherence to proton pump inhibitors in daily clinical practice. Aliment Pharmacol Ther. 2006;24(2):377-385.

14. Gunaratnam NT, Jessup TP, Inadomi J, Lascewski DP. Sub-optimal proton pump inhibitor dosing is prevalent in patients with poorly controlled gastro-oesophgeal reflux disease. Aliment Pharmacol Ther 2006;23(10):1473-1477.

15. Barrison AF, Jarboe LA, Weinberg BM, Nimmagadda K, Sullivan LM, Wolfe MM. Patterns of proton pump inhibitor use in clinical practice. Am J Med. 2001;111(6):469-473. 
16. Katsuki H, Yagi H, Arimori K, et al. Determination of $\mathrm{R}(+)$ - and $\mathrm{S}(-)$-lansoprazole using chiral stationary-phase liquid chromatography and their enantioselective pharmacokinetics in humans. Pharm Res. 1996;13(Apr):611-615.

17. Kapidex ${ }^{\circledR}$ [prescribing information]. Takeda Pharmaceutical, North America: Deerfield, IL. 2009.

18. Katsuki H, Hamada A, Nakamura C, Arimori K, Nakano M. Role of CYP3A4 and CYP2C19 in the stereoselective metabolism of lansoprazole by human liver microsomes. Eur J Clin Pharmacol. 2001;57(10):709-715.

19. Vakily M, Zhang W, Wu J, Atkinson SN, Mulford D. Pharmacokinetics and pharmacodynamics of a known active PPI with a novel dual delayed release technology, dexlansoprazole MR: a combined analysis of randomized controlled clinical trials. Curr Med Res Opin. 2009;25(3):627-638.

20. Mayer MD, Vakily M, Witt G, Mulford DJ. The pharmacokinetics of TAK-390MR $60 \mathrm{mg}$, a dual delayed release formulation of the proton pump inhibitor TAK-390, and lansoprazole $60 \mathrm{mg}$ : a retrospective analysis [abstract]. Gastroenterology. 2008;134 4 Suppl 1:A176.

21. Metz MC, Vakily M, Dixit T, Mulford D. Review article: dual delayed release formulation of dexlansoprazole MR, a novel approach to overcome the limitations of conventional single release proton pump inhibitor therapy. Aliment Pharmacol Ther. 2009;29(9):928-937.

22. Zhang W, Wu J, Atkinson S.Pharmacokinetic (PK), pharmacodynamic (PD), and safety evaulation of single and multiple $60 \mathrm{mg}, 90 \mathrm{mg}$, and $120 \mathrm{mg}$ oral doses of modified release TAK-390 (TAK-390MR) and $30 \mathrm{mg}$ oral doses of lansoprazole (Lan) in healthy subjects. [abstract]. Gastroenterology. 2007;132(4 Suppl 2):487.

23. Lee RD, Vakily M, Mulford D, Wu J, Atkinson SN. Clinical trial: the effect and timing of food on the pharmacokinetics and pharmacodynamics of dexlansoprazole MR, a novel dual delayed release formulation of a proton pump inhibitor - evidence for dosing flexibility. Aliment Pharmacol Ther. 2009;29(8):824-833.

24. Lee RD, Mulford D, Wu J, Atkinson SN. The effect of time-of-day dosing of TAK-390MR on the pharmacokinetics and pharmacodynamics of TAK-390: evidence for dosing flexibility with this dual delayed release proton pump inhibitor [abstract]. Gastroenterology. 2009;136 5 Suppl 1: A-440.

25. Pehlivanov ND, Olyaee M, Sarosiek I, McCallum RW. Comparison of morning and evening administration of rabeprazole for gastrooesophageal reflux and nocturnal gastric acid breakthrough in patients with reflux disease: a double-blind cross-over study. Aliment Pharmacol Ther. 2003;18(9):883-890.

26. Hongo M, Ohara S, Hirasawa Y, Abe S, Asaki S, Toyota T. Effect of lansoprazole on intragastric $\mathrm{pH}$. Comparison between morning and evening dosing. Dig Dis Sci. 1992;37(6):882-890.
27. Fraser AG, Sawyerr AM, Hudson M, Smith MS, Pounder RE. Morning versus evening dosing of lansoprazole $30 \mathrm{mg}$ daily on twenty-fourhour intragastric acidity in healthy subjects. Aliment Pharmacol Ther. 1996;10(4):523-527.

28. Czerniak R, Vakily M, Wu J. TAK-390MR, a novel dual delayed release formulation of a PPI, is bioequivalent when administered as granules sprinkled over applesauce. [abstract]. Am J Gastroenterol. 2008;103 Suppl S:S4-S5.

29. Vakily M, Lee RD, Wu J, Gunawardhana L, Mulford D. Drug interaction studies with dexlansoprazole modified release (TAK-390MR), a proton pump inhibitor with a dual delayed-release formulation: results of four randomized, double-blind, crossover, placebo-controlled, single-centre studies. Clin Drug Invest. 2009;29(1):35-50.

30. Lee RD, Wu J, Vakily M, Mulford D. Effect of hepatic impairment on the pharmacokinetics of TAK-390MR (modified release) [abstract]. Clin Pharmacol Ther. 2008;83 Suppl 1:S95.

31. Vakily M, Zhang W, Wu J, Mulford D. Effect of age and gender on the pharmacokinetics of a single oral dose of TAK-390MR (modified release) [abstract]. Clin Pharmacol Ther. 2008;83 Suppl 1:S96.

32. Zhang W, Wu J, Vakily M. Pharmacokinetics of TAK-390MR (modified-release) 30, 60, and $90 \mathrm{mg}$ in subjects with symptomatic, non-erosive gastroesophageal reflux disease (GERD) [abstract]. Clin Pharmacol Ther. 2008;83 Suppl 1:S96.

33. Sharma P, Shaheen NJ, Perez MC, et al. Clinical trials: healing of erosive oesophagitis with dexlansoprazole MR, a proton pump inhibitor with a novel dual delayed-release formulation - results from two randomized controlled studies. Aliment Pharmacol Ther. 2009;29(7):731-741.

34. Metz DC, Howden CW, Perez MC, Larsen L, O’Neil J, Atkinson SN. Clinical trial: dexlansoprazole MR, a proton pump inhibitor with dual delayed-release technology, effectively controls symptoms and prevents relapse in patients with healed erosive oesophagitis. Aliment Pharmacol Ther. 2009;29(7):742-754.

35. Howden C, Larsen L, Palmer R, Perez MC. Placebo-controlled trial of 2 doses of TAK-390MR, a PPI with novel dual delayed release technology, as maintenance treatment for patients with healed erosive esophagitis (EE). Aliment Pharmacol Ther. 2009;30(9):895-907.

36. Fass R, Chey WD, Zakko SF, et al. Clinical trial: the effects of the proton pump inhibitor dexlansoprazole MR on daytime and nighttime heartburn in patients with nonerosive reflux disease. Aliment Pharmacol Ther. 2009;29(12):1261-1272.

37. Zhang W, Wu J, Atkinson SN. Effects of dexlansoprazole MR, a novel dual delayed release formulation of a proton pump inhibitor, on plasma gastrin levels in healthy subjects. J Clin Pharmacol. 2009;49(4):444-454.

38. Vakily M, Wu J, Atkinson S. Effect of single oral doses (90 and $300 \mathrm{mg}$ ) of TAK-390MR on QT intervals. [abstract]. Clin Pharmacol Ther. 2007;81 Suppl 1:S26.
Clinical and Experimental Gastroenterology

\section{Publish your work in this journal}

Clinical and Experimental Gastroenterology is an international, peerreviewed, open access journal, publishing all aspects of gastroenterology in the clinic and laboratory, including: Pathology, pathophysiology of gastrointestinal disease; Investigation and treatment of gastointestinal disease; Pharmacology of drugs used in the alimentary tract;

\section{Dovepress}

Immunology/genetics/genomics related to gastrointestinal disease. This journal is indexed on CAS. The manuscript management system is completely online and includes a very quick and fair peer-review system. Visit http://www.dovepress.com/testimonials.php to read real quotes from published authors. 